\title{
On the Choice of Strategy in Electricity Companies Marketing
}

\author{
Lijuan Zhang ${ }^{1}$, Ningning $\mathrm{Li}^{2}$, and Hua Huang ${ }^{3}$ \\ 1) School of economics and management, Northeast Dianli University, Jilin, Jilin, China (zhanglijuannedu@163.com) \\ 2) Inner Mongolia Xilin River Coal Chemical Co., Ltd. Xinlingol, Inner Mongolia, China (liningning_rabbi@163.com) \\ 3) Inner Mongolia Xilin River Coal Chemical Co., Ltd. Xinlingol, Inner Mongolia Province, China (hh_xlh@163.com)
}

Abstract - With the further advancement of the electric power markets reform, the electricity companies' marketing got rapid development. But it also need to be further improved. This paper aims to analyze how to make a choice of marketing strategy for electricity companies from the perspective of marketing concept, team building, product, price, distribution network and promotion and so on.

Keywords—electricity companies, marketing, strategy

\section{论电力企业市场营销策略选择}

\author{
张丽娟 ${ }^{1}$ 李宁宁 ${ }^{2}$ 黄华 $^{3}$ \\ 1) 东北电力大学经济管理学院, 吉林, 吉林, 中国 \\ 2) 内蒙古锡林河煤化工有限责任公司, 锡林郭勒, 内蒙古, 中国 \\ 3) 内蒙古锡林河煤化工有限责任公司, 锡林郭勒, 内蒙古, 中国
}

摘 要 随着电力体制改革的进一步深化, 电力企业的市场营销得到了长足的发展。但是电力企业市场营销还需要进一步提高。 从营销观念、队伍建设、产品、价格、分销网络和促销等几个方面来分析电力市场如何选择营销策略。

关键词 电力企业，市场营销，策略

1. 引言

营销是公司经营活动中一项十分重要的工作，营销工 作的好坏直接关系到企业的利润多少。而电力行业作为一 种特殊的垄断行业，多年来靠一种不合理、不公平的竞争 规则，年复一年，日复一日地稳定地获取着利润。随着电 力体制改革的进一步深化，电力企业的领导和员工都对市 场营销工作重视起来, 电力企业的市场营销在策略选择过 程中要从以下几个方面入手。

\section{2. 更新市场营销观念}

电力市场营销的开展应立足于 “电网是基础, 技术是 支撑, 服务和管理是保障” 的原则。应当充分利用电力行 业 “两网” 改造的有利时机逐步解决供配电网络的 “瓶颈”。 建立基于买方市场的要求的新型电力市场营销理念, 进行 商业化运营, 法制化管理。同时, 加强供电局的需求信息
收集功能。供电局是电力系统直接面对用户、面对市场的 窗口部位, 也是实现电力销售的最终环节。必须彻底改变 供电局在长期计划经济和卖方市场形式下形成的传统管理 模式, 变单纯的电力抄表收费为主动的推销、扩销、开发 市场, 使供电局在电力营销中成为一个功能齐全, 有相当 分析、调研、开拓能力的基层营销核心。

\section{3. 建立高素质营销队伍}

首先，在选拔营销人员时要高标准严要求，要舍得将 文化、业务等素质好的人员优先选择到主要的营销岗位, 并提高营销岗位的待遇。其次，应加强对营销人员的教育 培训工作, 既要进行营销理论的系统培训, 又要在营销实 践中加大考核力度，不断选拔优秀的营销服务人员走上领 导岗位。最后，应树立以 “人” 为本的经营理念，并以这 种理念来塑造企业文化, 以 “电力客户完全满意” 作为我 
们一贯处事的态度，培养营销人员具有 “人人为我，我为 人人” 的思想意识, 使之成为一种自觉意识。企业应创造 充分发挥营销员工个性和创造力的环境, 营造一个 “学习 型组织”, 通过激励手段激发和调动营销员工的工作积极 性。

\section{4. 产品策略}

\section{1 分析电力产品特点}

电力产品的特点是可转换的形式多, 既可以作为一次 电力, 转换成光、热、动力等形式, 也可以作为终端能源 使用。消费者极其广泛、多样, 顾客群大。同质性强, 无 论何时、何地, 其频率、电压相同。而且电力产品不能存 储, 产、供、销同时完成。

\section{2. 电力需求预测}

电力需求预测要在分析宏观环境的基础之上, 也就是 在分析人口环境、经济环境、自然环境、技术环境、政治 环境和文化环境的基础上，对电力市场进行市场细分。并 在连贯性、相关性和类推的原则指导下，利用用电单耗法 等预测方法来进行电力需求的电量预测和负荷预测。

\section{3 加强产品安全质量}

通过改善电网结构, 提高供电可靠性, 改善电能的质 量, 来提高对客户的吸引力。产品质量是营销的基础保证, 要加大城网和农网的改造力度, 加快一户一表的改造步伐, 改善电网结构, 提高供电可靠性。

\section{4 全方位提供的优质服务}

必须把不断提高优质服务水平作为促进电力的市场营 销的自觉行为, 并体现在整个生产经营的全过程和各个环 节, 使每一个部门, 每一个员工都为企业的社会形象负责, 真正树立全员营销的观点，与客户建立并保持一种共同发 展的新型供用电关系。

\section{5. 价格策略}

在国家政策范围内实行弹性管理策略。

1. 利用国家目录电价启动高耗能企业和其他有潜力的 用电大户。

2.采用 “折扣” 方法, 实行 “梯度” 电价。

3. 实行季节性电价。

4.根据实际情况减免贴费及各种附加费, 清理各种乱 收费, 真正减轻企业负担, 充分释放企业的用电潜能。

电价政策不能只涉及卖电侧, 还应涉及电力商品的上
游 (即发电侧)。出发点就是降低购电价格, 这样才能在保 证省公司利润基础上, 让利于用户, 才能保住市场并发展 市场。

\section{6. 分销网络}

销售网络是贯彻营销策略的基础, 是正确的营销策略 能否顺利进行的关键。由于电力商品的特殊性, 使得电力 公司对分布在供电区内的许多用户只能销售一种产品, 因 此其销售网络的建设相对较为简单。应组织人员从人口、 区域面积、供电量等几个方面研究确定电力企业规模, 做 到既缩小规模, 又保证服务。规模大的可一分为二, 变为 两个独立实体, 配电线路开放, 开展竞争, 以优质服务来 吸引客户。原有的售电人员在完成本职工作的基础上, 肩 负着宣传电力商品的任务。各类用电服务中心的外勤和内 勤人员应既有分工又有合作。

\section{7. 促销策略}

\section{1 广告}

应结合电力特点, 采用说服性内容, 运用比较的方法、 气氛或印象、个性的象征、技术特色、科学证据等不同的 表达方式来显现。选择宣传媒体要考虑媒体影响和成本的 概念。清洁、高效、快捷是电能的优势, 使用电能符合国 家的环保能源政策，受到国家政策的支持，特别是在城区 日益严重的环境污染使人们对清洁能源的应用越来越重

视, 以此为契机作为能源市场的切入口, 在宣传和推广上 打出环保能源的品牌, 做好能源市场的扩张, 并成为形象设 计的主要特点宣传重点是与老百姓生活密切相关且用电量 较大的电器产品安全使用知识并体现国家能源环保政策。

\section{2 公共关系}

公共关系是一个重要的营销工具, 电力部门不仅要建 设性地与政府、企业建立关系, 而且也要与大量的感兴趣 的公众建立关系。其目标是: 建立电力公司的知名度以吸 引大家的注意力, 通过與论宣传以增加电力公司的可信度, 刺激基层电业部门和营销队伍的建设, 降低促销成本。选 择的主要营销公关工具有介绍电力知识和电力企业情况的 公开出版物、新闻报道、社会文化活动和公益服务活动等。

未来的电力营销市场是一个买方市场。要建立起适应 买方市场需要的新型电力营销理念, 即以市场需求为导向, 以优质服务为手段, 随时随地为用户提供质优、价廉的清 洁能源, 建立一个能适应商业化运营、法制化管理, 分层 高效运作, 功能齐备, 具有较高服务水准, 充满市场活力 的市场营销体系和机制。 


\section{参考文献(References)}

[1] W. Huang, "On Electricity Companies Marketing," Journal of Chongqing University of Technology(Social Science), vol. 26, no. 5, pp. 46-48, 2012.

[2] X. Yang, "On Electricity Companies Marketing in our Country," Manager'Journal, no. 19, pp. 144, 2011.

[3] H. Wang, "On the Combination Marketing of Chinese Electric
Power Enterprise," Journal of Lanzhou Commercial College, vol. 25, no. 5, pp. 7-11, 2009.

[4] Y. T. Chen, "The Reform of Electric Power Company and Marketing Research," Master's Degree Dissertation of Chongqing University, pp. 32-34, 2003.

[5] L. Lin, "On Marketing Strategy of Electricity Companies," Shanghai University of Electric Power, no. 5, pp. 35-36, 2001. 